\title{
É POSSÍVEL O COLONIZADOR SE AUTO-DESCOLONIZAR?
}

\author{
JORGE HILTON DE ASSIS MIRANDA
}

Mestre em Educação e Contemporaneidade pela Universidade Estadual da Bahia (UNEB); especialista em História das Culturas Afro-brasileiras pela Faculdade de Tecnologia e Ciências (FTC) e Cientista Social pela Universidade Federal da Bahia (UFBA) Doutorando em Estudos Étnicos e Africanos pela Universidade Federal da Bahia. Integra o grupo de pesquisa Estudos Étnicos (PÓS-AFRO/UFBA. Professor da Faculdade Montessoriano. ORCID: 000-020-9371-

0743. Email: zulu.hilton@gmail.com 


\section{É POSSÍVEL O COLONIZADOR SE AUTO-DESCOLONIZAR?}

O presente estudo é um diálogo que se relaciona com a teoria pós-colonial e decolonial a partir de reflexões de minha pesquisa no mestrado intitulada Perspectivas de rappers brancos/as brasileiros/as sobre as relações raciais - um olhar sobre a branquitude (MIRANDA, 2015). Reflete sobre o pensamento de autores africanos e da diáspora, negros e não-negros, desenvolvendo conceitos, algumas vezes próprios, que se conectam com a temática da branquitude na busca de maior entendimento do tema sob novas abordagens. Analiso letras de música Rap. Proponho uma discussão na perspectiva de vislumbrar o movimento de descolonização para além dos subalternizados, tentando responder se é possível que o próprio colonizador, possa expurgar de si o complexo de superioridade, mudando valores, enxergando a humanidade do outro, assumindo-se responsável em ações pela equidade e justiça racial. Em termos contemporâneos estendemos para todo indivíduo branco que se omite frente ao racismo.

Palavras chave: Auto-descolonização; Branquitude; Decolonialidade; Pós-colonialidade; Racismo.

\section{IS IT POSSIBLE FOR THE COLONIZER TO SELF-DECOLONIZE ?}

The present study is a dialogue that relates to postcolonial and decolonial theory based on reflections of my research in the master's degree entitled "Perspectives of Brazilian white rappers on race relations - a look at whiteness" (2015). It reflects on the thinking of African and diaspora authors, black and nonblack, developing concepts, sometimes of their own, that connect with the theme of whiteness in the search for a greater understanding of the theme under new approaches. I analyze Rap lyrics. I propose a discussion in the perspective of glimpsing the decolonization movement beyond the subalternized ones, trying to answer if it is possible that the colonizer himself may purge the superiority complex, changing values, seeing the humanity of the other, assuming responsibility in actions for equity and racial justice. In contemporary terms we extend to every white individual who omits against racism.

Keywords: Self-decolonization; Whiteness; Decoloniality; Post-coloniality; Racism.

\section{¿ES POSIBLE QUE EL COLONIZADOR SE AUTODESCOLONIZE?}

El presente estudio es un diálogo que se relaciona con la teoría postcolonial y decolonial a partir de reflexiones de mi investigación en el máster titulado "Perspectivas de raperos blancos brasileños sobre las relaciones raciales - una mirada sobre la branquitud" (2015). En el caso de los autores africanos y de la diáspora, negros y no negros, desarrolla conceptos, algunas veces propios, que se conectan con la temática de la branquitud en la búsqueda de mayor entendimiento del tema bajo nuevos abordajes. Analizo letras de canciones Rap. Propongo una discusión en la perspectiva de percibir el movimiento de descolonización más allá de los subalternates, tratando de responder si es posible que el propio colonizador, pueda purgar de sí mismo el complejo de superioridad, cambiando valores, viendo el La humanidad del otro, asumiendo la responsabilidad en acciones por la equidad y la justicia racial. En términos contemporáneos nos extendemos a cada individuo blanco que omite contra el racismo.

Palabras clave: Auto-descolonización; blancura; descolonialidad; postcolonialidad; Racismo. 


\section{É POSSÍVEL O COLONIZADOR SE AUTO-DESCOLONIZAR?}

\section{Descolonização e Branquitude}

Historicamente, a descolonização é uma ação de libertação e independência das antigas colônias. Pela perspectiva epistemológica, vem caracterizando-se enquanto um movimento crítico e de empoderamento dos povos subalternizados, com base na produção de estudos pruralistas, "em termos de raça-etnia, gênero, trabalho, conhecimento, sexo, religião-espiritualidade e linguagem" (BARBOSA, 2012, p.174). Também chamados de estudos "descoloniais", "descolonizadores", a partir do lugar dos sujeitos envolvidos, pautam-se um novo olhar científico, frente ao conhecimento hegemônico-eurocêntrico.

A natureza violenta e desumanizadora da colonização foi amplamente abordada por autores como Fanon (1968, 2008), Memmi (2007), Bhabha (1998), Césaire (1978), Hall (2003) e vários outros. Muito se investiga sobre o colonizado, o que sofre a violência, subalternização, e as consequências negativas simbólicas e matérias, porém há uma lacuna de análise sobre o colonizador, o agente que subjulga, violenta e se mantém, segundo Memmi (2007), historicamente detentor de privilégios. Tais prerrogativas se tornam herança para um grupo racial, é o que se chama de branquitude, ou seja, uma condição de privilégios herdada pelas pessoas brancas, fruto da representação dessa raça como modelo universal de humanidade (PIZA, 2003).

Branquitude enquanto tema tornou-se uma emergência recente na investigação científica brasileira. Lembrando que a investigação e análise sobre a identidade racial branca procura problematizar aquele que numa relação opressor/oprimido exerce o papel de opressor, ou por outras palavras, o lugar do branco numa situação de desigualdade racial. (...) Vale lembrar que a teoria anti-racista, de maneira geral, tem restringido em pesquisar o oprimido, deixando de lado o opressor. (...) De modo breve gostaria de dizer que as pesquisas sobre a branquitude ao focar o branco em suas pesquisas, não propõem que se negligenciem as pesquisas a respeito da negritude, e sim, chamam a atenção e procuram preencher uma lacuna nas teorias das relações raciais. (CARDOSO, 2008, p.610).

\footnotetext{
${ }^{1}$ Movimento fortemente inspirado nos trabalhos de Frantz Fanon e W.E.B Du Bois, tem alguns dos interlocutores, autores como Enrique Dussel, Nelson Maldonado Torres, Walter Mignolo, Ramon Grosfuguel, e Gloria Anzaldúa
} 
Enquanto reflexo do racismo, a branquitude possui várias facetas e graduações caracterizando-se de modo particular conforme a cultura local. A pessoa considerada branca no Brasil, pode ser vista como latina nos Estados Unidos ou mesmo negra em algum país europeu. A depender dos traços fenotípicos, mesmo no Brasil, dentro de uma mesma cidade, alguém pode ser visto como branco por uns, e negro por outros. Em qualquer situação, diante da pessoa de fenótipo preto, que remonte a África negra, o indivíduo de fenótipo branco terá vantagens, que aumentam conforme se aproxime do padrão estético europeu. Para Liv Sovik (2009, p.50).

\begin{abstract}
A branquitude é um atributo de quem ocupa um lugar social no alto da pirâmide, é uma prática social e um exercício de função que reforça e reproduz instituições, é um lugar de fala para o qual uma certa aparência é condição suficiente. A branquitude mantém uma relação complexa com a cor da pele, formato de nariz e tipo de cabelo.
\end{abstract}

A branquitude é uma herança que foi reforçada pela colonização. Sobre a condição de colonizador, Memmi (2007) retrata dois perfis: o que mantém inalterado seu status "natural" de agente imperialista, e o que defende o colonizado e tenta negar a própria posição. Em ambos os casos há uma percepção sobre si, sobre seu lugar numa hierarquia sócio-racial. Analisá-la é uma necessidade.

Em termos gerais o olhar sobre o próprio privilégio é assimétrico. Essa auto percepção é tema de constantes debates no meio acadêmico. O indivíduo branco de hoje, sabe perfeitamente valorizar sua herança europeia quando lhe convém, mas frequentemente tenta negá-la quando é associado ao passado de atrocidades cometidas pelo colonizador. Dentre outras, a percepção crítica sobre si está relacionada a uma postura de neutralidade (que defino como consciência constante da situação de privilegiado) e invisibilidade (inconsciência, constante ou não, da situação de privilegiado). Na atualidade, frente aos privilégios, o indivíduo "neutro" mantém posicionamento ativo, dissimulado, intencional de omissão e indiferença. Já o indivíduo "invisível” sobre si, mantem-se em postura passiva, não dissimulada, não intencional de acomodação.

Essa percepção crítica sobre si será fator determinante para responder a pergunta norteadora deste estudo "é possível o colonizador se descolonizar?". 


\section{Quem é o inimigo? - Sobre a humanidade em si e no outro}

Minha motivação para estudar o tema branquitude partiu de inquietações, dentre as quais surgidas no III Encontro ${ }^{2}$ Baiano de Hip-Hop. Em um debate relacionado ao fim das injustiças sociais e raciais, o rapper e panafricanista ${ }^{3}$ conhecido como Menelik, do extinto grupo Júri Racional, gritou: “morte aos brancos!". O rapper do município de Alagoinhas conhecido como MC Osmar foi conversar com ele, dizer que se sentiu ofendido e segundo conta, foi hostilizado. O mal-estar foi geral e, a partir dali, não se conseguiu continuar a atividade, devido ao "bate-boca" gerado.

Talvez no contexto atual, episódios como esse não acontecessem, em função de uma maior maturidade entre os adeptos da música Rap e, acima de tudo, compreensão de que "nem todo branco é inimigo, nem todo preto é aliado"4. Basta recordar o massacre na Nigéria, com mais de 2000 (dois mil) mortos em um único dia, promovido pelo Boko Haram ${ }^{5}$ a seus pares, também pretos, por serem de outra religião. Na experiência brasileira muitos são os exemplos, principalmente quando se referem aos crimes de ódio, cometidos por neo-pentecostais, contra adeptos de religiões de matriz africana. Negros que praticam e incitam a violência contra outros negros em nome de uma crença religiosa. A história de luta de diferentes Movimentos Sociais pelo mundo revela que radicalidade (HELLER, 1982; FREIRE, 2000) tem o seu lugar, porém, muitas vezes, em função de interpretações generalistas e da forte sobreposição do componente emocional sobre o racional, pode incidir em graves erros. Segundo Fanon (2008), o negro que prega o ódio ao branco é tão infeliz quanto o que quer embranquecer a raça. "Morte aos brancos!"” é diferente de "Morte ao sistema branco!" . É o sistema, a estrutura que deveria ser considerada inimiga. Os equívocos de natureza individual e institucional demandam atenções diferenciadas, sendo as primeiras mais relacionadas ao campo pedagógico e a segunda, mais ao administrativo-jurídico. Para Freud (1930), os seres humanos revelam uma tendência inata

\footnotetext{
${ }^{2}$ Aconteceu em 2004, na cidade de Vitória da Conquista.

${ }^{3}$ Pan-africanismo é um movimento político, filosófico e social que propõe a união de todos os povos da África, como forma de promoção e defesa dos seus direitos e a potencialização da voz do continente no contexto internacional.

${ }^{4}$ Pan-africanismo é um movimento político, filosófico e social que propõe a união de todos os povos da África, como forma de promoção e defesa dos seus direitos e a potencialização da voz do continente no contexto internacional.

${ }^{5}$ Pan-africanismo é um movimento político, filosófico e social que propõe a união de todos os povos da África, como forma de promoção e defesa dos seus direitos e a potencialização da voz do continente no contexto internacional.

${ }^{6}$ Sistema de poder hegemônico, estruturante e institucionalizado que opera reproduzindo desigualdades em diferentes níveis.
} 
para o descuido, irresponsabilidade e a agressividade. O poder no 'direito', em oposição ao poder do indivíduo, constitui o passo decisivo da "civilização". Assim, grande parte das lutas da humanidade centraliza-se em torno da tarefa de encontrar uma acomodação (que traga felicidade) entre a reivindicação do indivíduo e as reivindicações culturais do grupo.

O Rap é música de origem negra. Faz parte do Hip-Hop, Cultura constituída com a contribuição de outros grupos étnico-raciais não-negros, sendo esse um dos fatores que substanciam o argumento da Organização Mundial Zulu Nation para instituir o respeito enquanto um valor fundamental a ser seguido pelos adeptos dessa expressão artística. Como representante dessa entidade, consegui, em abril de 2010, viabilizar a vinda do DJ Afrika Bambaataa pela primeira vez à Bahia. Em sua fala, o mesmo reforçou a importância do respeito e do comprometimento solidário com o outro e com o planeta:

O Rap é música de origem negra. Faz parte do Hip-Hop, Cultura constituída com a contribuição de outros grupos étnico-raciais não-negros, sendo esse um dos fatores que substanciam o argumento da Organização Mundial Zulu Nation para instituir o respeito enquanto um valor fundamental a ser seguido pelos adeptos dessa expressão artística. Como representante dessa entidade, consegui, em abril de 2010, viabilizar a vinda do DJ Afrika Bambaataa pela primeira vez à Bahia. Em sua fala, o mesmo reforçou a importância do respeito e do comprometimento solidário com o outro e com o planeta:

Saiba que a África é de onde você veio, é o útero de onde você veio, de onde veio todo o mundo. A gente tem que ter respeito pelos negros, pelos marrons, amarelos, vermelhos, brancos e todas as diferentes civilizações que temos espalhadas por esse grande planeta. Se formos só pessoas que gostamos de Hip-Hop, Samba, Bossa Nova, House, Techno, Electro sem se importar com que os políticos estão fazendo, sem se ligar com o que está acontecendo com a "Mãe Terra", o que adianta? (...) Se você olha para o outro e não se vê no outro? Então parem de se odiar, comecem a ter amor por si mesmo, comecem a saber de onde vocês vieram, pois vocês são deuses e deusas. (BAMBAATAA, 2010) ${ }^{7}$.

Bambaataa faz referência à importância do comprometimento político com as mudanças; da empatia e do respeito pelo outro e pelo planeta. Seu estímulo à alteridade conforme Hall (2006) em hipótese alguma deve significar "fechar os olhos" para as desigualdades e demais injustiças sociorraciais; tampouco ser confundido com o discurso do "somos todos iguais". Em

${ }^{7} \mathrm{O}$ trecho foi transcrito do vídeo que contém a fala completa de Bambaataa, que pode ser acessado em: http://youtu. be/SUOeq94021s

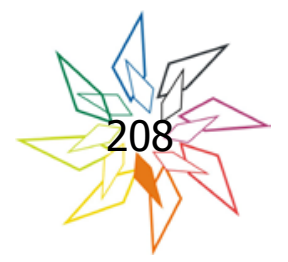


sua fala, embora o fato de o continente africano ser o berço da humanidade, somos diferentes étnico-racialmente, em gostos musicais etc. Seu discurso é um alerta, conforme Fanon (2008, p.27), para se pôr fim ao que chama de "narcisismo mórbido", caracterizado por um "ciclo vicioso", dentre o qual "o branco está fechado na sua brancura. O negro na sua negrura". E que vale para os demais grupos étnico-raciais. Fanon (idem, p.28) defende que o individuo deve "tender ao universalismo inerente à condição humana". Condição essa que Paulo Freire descreve como "compromisso radical com o homem concreto. Compromisso que se orienta no sentido de transformação de qualquer situação objetiva, na qual o homem concreto esteja sendo impedido de ser mais" (FREIRE, 1983, p.12), impedido de se manter em constate busca por situações melhores individual e coletivamente.

O ser humano e sua natureza constituem-se histórica e ontologicamente em duas direções: humanização e desumanização (FREIRE, 1996). A primeira é vocação histórica voltada para o "ser mais"; a segunda é a deturpação dessa vocação, o "ser menos" em função de uma "ordem" injusta, que incide diferentemente sobre oprimido e opressor (idem, 1987 citado por JESUS, 2010). Nesse processo, eminentemente relacional, a humanização só se faz, segundo Fanon (2008, p.180), pelo reconhecimento do outro:

O homem só é humano na medida em que ele quer se impor a um outro homem, a fim de ser reconhecido. Enquanto ele não é efetivamente reconhecido pelo outro, é este outro que permanece o tema de sua ação. É deste outro, do reconhecimento por este outro que dependem seu valor e sua realidade humana. É neste outro que se condensa o sentido de sua vida.

Em sintonia com o pensamento de Paulo Freire, Fanon defende a necessidade de "reconhecer" o outro em seu direito de "ser mais", em uma cidadania para além das convenções nacionalistas, "em direção a um novo humanismo" (FANON, 2008, p.180), contrário ao projetado pela concepção ideológica europeia. Para ambos os autores, a possibilidade de "desumanização" é um "risco" real, daí a exigência da "luta" que atestará "que ultrapasso a vida em direção a um bem supremo que é a transformação da certeza subjetiva, que tenho do meu próprio valor, em verdade objetiva universalmente válida" (FANON, 2008, p.180). Tal visão se conforma com o paradigma de humanidade da região oeste da África, pelo qual Nogueira compartilha:

O modelo que emerge deste paradigma tem muitas características. Ele assume que todos os seres humanos deveriam ser [1] livres para crescerem e realizarem seus mais altos potenciais como seres espirituais [distinto da religiosidade, necessariamente]; [2] livres da opressão e dos ambientes humanamente degradantes; [3] livres para viver cooperativamente com qualquer ser humano que respeite sua humanidade; [4] livres para desenvolver o conhecimento sobre si mesmo (...); livres para atingir a dignidade humana sem barreiras artificiais 
que negam seu acesso aos campos de crescimento humano. (AKBAR, 2004, p.45 citado por NOGUEIRA, 2014, p.52).

Uma possível auto-descolonização do branco passa invariavelmente pelo reconhecimento da humanidade do outro, e da existência do racismo. Um processo permanentemente necessário para o que Bhabha (1998) chama de negociação.

\section{O branco denegrido e o branco africanizado}

Em minha pesquisa no mestrado envolvendo rappers brancos brasileiros, dois deles se declararam brancos, porém de modo adjetivado. MC Osmar se classificou como "branco africanizado" e o rapper Preto Du "branco denegrido". Tais denominações são caminhos para se entender o papel e limitações de indivíduos brancos na luta contra o racismo.

"Denegrida" é uma canção autobiográfica em que Preto Du, dentre outras coisas, se afirma racialmente e justifica seu pseudônimo:

Meu nome é Preto Du, e não me venha perguntar

Antes que você pergunte, eu já vou lhe adiantar

Por que Preto no meu nome se eu tenho a pele clara?

“- A resposta é bem clara”. Ã, ã, é bem escura (...)

Alimento os sentimentos que habitam no meu corpo

Os pensamentos tão escritos para quando eu estiver morto

Louco? Sou sim, pode me trancar no hospício

Mas mudar minha ideologia vai ser difícil (...)

Se tem negros completamente embranquecidos

Eu sou um branco completamente denegrido

\footnotetext{
${ }^{8}$ Denegrida era o nome do anterior grupo de Preto Du, idealizado pelo mesmo enquanto fã da banda Simples Rap'ortagem. Ele informa ter se inspirado nos versos da música Quadro Negro (2004-2005): "Se na prova der branco na memória, vamos denegrir a sua mente com a nossa história", na época, cantados por mim, Paula Azeviche e Gueléo, ambos negros. Conta Preto Du que ficou um bom tempo intrigado, tentando compreender o sentido da palavra "denegrir" no contexto da canção. Cf. música Quadro Negro - http://www.simplesrap.com/2010/05/quadro-negro-2005.html Cf. música Denegrida - https://www.youtube.com/watch?v=iT2Fia3-e-0
} 
Antes de analisar a letra, considero importante fazer algumas considerações. Essa era uma obra inacabada do anterior grupo de Rap de Preto Du. Aproximadamente $80 \%$ do conteúdo estava pronto, mas para que incorporássemos a mesma no repertório da Simples Rap'ortagem 9 , segundo ele, faltava o meu aval, apontando criticamente o que deveria ser corrigido e acrescentado. Uma vez que eu tinha maior experiência e habilidade com o tema e com os versos, conseguiria mais facilmente converter em rimas algumas de nossas ideias, fruto de constantes diálogos informais. Com isso, ele buscava evitar que sua autobiografia musical incorresse em afirmações comprometedoras e equivocadas na perspectiva crítica da militância negra. Assim, entrei como coautor da obra ${ }^{10}$.

Sobre seu nome artístico, eu considero: "O saque tá no pseudônimo, na provocação / Preto Du, aquele que não precisa não / Se dizer, afirmar afrodescendente / Negro, pra ser aceito entre a gente". Em suma, como veremos, seu pseudônimo está coerente com o que defende na letra. Objetiva chamar a atenção para um tema em que os seus não dão muita importância. Seria um "tiro no pé"ll se o mesmo se afirmasse negro. Ao contrário, se declara branco, reconhece e questiona os próprios privilégios, ao passo que direciona toda a crítica a seu próprio grupo racial pelos vários equívocos. Para ele, não há obviedade em torno do significado em usar o pseudônimo Preto Du. Diferente do que alguns poderiam deduzir, não é "claro", nem tão fácil entender. Em sentido inverso, provocativamente, afirma "é bem escuro", fazendo uma referência direta à positivação da palavra "escuro" e à tensão racial a qual problematiza.

No verso "se tem negros completamente embranquecidos, sou um branco completamente denegrido", sem negar a sua identidade, ele inverte a lógica do embranquecimento, "enegrecendo" suas ideias. Outro trecho deixa explícito como se define a partir de uma negação comumente usada para defender/caracterizar brancos que se afirmam negros e/ou que se simpatizam com a cultura de matriz africana: "Mais negro que muitos negros", na moral / Se eu falasse isso, me sentiria irracional / Sou Eduardo Filho, que no trilho racial / É branco no nome e privilegio social". O "elogio" que Preto Du rejeita e critica é o mesmo que deixou o rapper Don Bruno "profundamente

\footnotetext{
${ }^{9}$ Denegrida era o nome do anterior grupo de Preto Du, idealizado pelo mesmo enquanto fã da banda Simples Rap'ortagem. Ele informa ter se inspirado nos versos da música Quadro Negro (2004-2005): "Se na prova der branco na memória, vamos denegrir a sua mente com a nossa história", na época, cantados por mim, Paula Azeviche e Gueléo, ambos negros. Conta Preto Du que ficou um bom tempo intrigado, tentando compreender o sentido da palavra "denegrir" no contexto da canção. Cf. música Quadro Negro - http://www.simplesrap.com/2010/05/quadro-negro-2005.html Cf. música Denegrida - https://www.youtube.com/watch?v=iT2Fia3-e-0

${ }^{10}$ Explico isso em função de possíveis dúvidas e curiosidades que alguns poderiam ter ao constatar que meu nome também aparece assinando a autoria da letra.

${ }^{11}$ Popularmente se refere a ação que se volta contra a própria pessoa.
} 
orgulhoso". Como nos conta no questionário que apliquei na pesquisa, buscando reconhecê-lo enquanto aliado na luta contra o racismo, o DJ do grupo Inquérito - que segundo Bruno "é um cara negro e estudioso sobre tudo o que envolve o passado, a escravidão" - assim se referiu a ele "mais preto que muitos pretos que eu conheço". No contexto de militância negra ${ }^{12}$, um branco se afirmar ou aceitar tal rótulo é um impropério, na medida em que, já privilegiado por sua condição de branco, se coloca mais uma vez como superior. Reflete insensibilidade e falta de empatia por não considerar as diferentes dimensões - histórica, política, social, psicológica, econômica etc. - do que representa "ser negro" em uma sociedade racista, que violenta estruturalmente essa identidade, ao passo que promove o embranquecimento ideológico e cultural da população.

Baseado no contexto da música, o termo "branco denegrido" pode servir para orientar a prática de outros brancos, dentro ou fora do Hip-Hop, que pretendem ser reconhecidos como aliados, como verdadeiramente antirracistas. Assim, o termo "branco denegrido" refere-se a uma postura política e não a uma afirmação de identidade, ao branco que se reconhece como peça da estrutura a qual o racismo opera, que faz mais que a "lavagem cerebral" sugerida por Gabriel O Pensador, se submetendo a uma espécie de "quimioterapia denegrecedora" contra as "células cancerígenas" do racismo.

Nesse processo, ele vê caírem de sua cabeça velhas crenças. Passa por diferentes sentimentos como culpa, vergonha, indignação, raiva... enfrenta seus "demônios", até que, vitorioso, se estabelece renovado em suas ações. Torna-se denegrido, não por se afirmar negro, mas por incorporar a perspectiva de denúncia da militância negra, que, dentre outras coisas, considera que os privilégios e a omissão sustentam as desigualdades sociorraciais. Em suma, o "branco denegrido" é um branco "sartreano" ${ }^{13}$.

Desenvolvendo mais o conceito, o "branco denegrido" se reconhece como branco, questiona os privilégios individuais e coletivos conferidos por esse fenótipo. Se identifica com a luta negra, aliando-se a essa, consciente de que o protagonismo cabe aos próprios negros. É o branco com as ideias "escurecidas", em que o próprio termo "denegrido" indica a incorporação de palavra com conotação socialmente negativa, de modo estratégico, positivada e politizada.

\footnotetext{
${ }^{12}$ Relaciona-se aos seguimentos dos Movimentos de negritude baianos que tive aproximação, como MNU (Movimento Negro Unificado), Níger Okan, Fórum de Entidades Negras da Bahia, CONEN (Coordenação Nacional de Entidades Negras na Bahia)

${ }^{13}$ REm referência a Jean-Paul Sartre, em seu famoso prefácio (1961) para a obra "Os condenados da Terra" (1968), de Frantz Fanon.
} 
Mc Osmar se define como "branco africanizado", ou seja, um branco que reivindica uma ancestralidade africana. Que pela história de colonização tenta negar uma herança vinculada a qualquer traço europeu. Pelas suas considerações, tem semelhança com o "branco denegrido", ao reconhecer privilégios, porém, diferente desse, não os questiona. Na música "Notícias no ar", MC Osmar ${ }^{14}$ diz:

Novas diretrizes, planos de governo,

Mas todos se omitem quando o assunto é o desemprego.

Uma pá de mano preso é o objetivo do sistema.

Preto e branco pobre é um revólver nas mãos do sistema.

De volta à cena pra reconstituição,

A lei gera problema e dificulta a regeneração.

A constituição prever nos seus artigos

Direito a ter direitos, mas só vejo aqui crime e castigo.

O "branco africanizado" diz respeito não necessariamente a uma postura, mas sim a uma construção de identidade. Não "corta a própria pele". Sua denúncia concentra-se no outro, na classe branca dominante que não lhe representa.

O "branco denegrido" traz uma dimensão curiosa de afirmação, pois sua existência se dá contrária a do "negro embranquecido", que busca os traços físicos da brancura. Em contraste, o "branco denegrido" não almeja se parecer fisicamente com o negro, o que pode se configurar um problema, na medida em que, involuntariamente, continuará acessando as vantagens ${ }^{15}$ da branquitude (CARDOSO, 2014). Porém, é a partir dos seus traços físicos que essa mesma branquitude será questionada, problematizada. Se buscasse a semelhança fenotípica do negro, poderia ser acusado de falso, superficial, de querer parecer o que não é. Considero a postura menos problemática que a dos brancos que negam a existência de privilégios e se autodeclaram negros meramente por possuir parentesco de pele escura ou porque defendem não existir brancos no Brasil (SOVIK, 2009). Se há DIREITO que possibilita a existência de "negros embranquecidos", que proporcionalmente haja DEVER que fomente a consciência de "brancos denegridos". Sigo nesse sentido, acreditando estar cumprindo uma obrigação ética.

\footnotetext{
${ }^{14}$ Canção gravada em 2010.

${ }^{15}$ Nesse ponto, tenho chamado a atenção do meu parceiro de banda, Preto Du, em relação a própria vaidade, uma vez que se destaca enquanto padrão de beleza. Aos cuidados que deve ter em relação a esta armadilha da branquitude.
} 


\section{É possível o branco expurgar o colono que há em si?}

Racismo é um sistema de poder, de dominação, forjado no pressuposto de uma superioridade racial, que cria e reproduz desigualdades e demais violências de ordem simbólica e material, através de mecanismos estruturais e institucionais. Nem todos que têm preconceito necessariamente o materializarão num gesto discriminatório. Ideias, julgamentos preconcebidos são características que se aprendem no convívio social. Diante do mesmo, a autorreflexão, ou uma ação pedagógica pode sensibilizar o indivíduo a mudar seu pensamento, evitando que chegue a discriminar.

As pessoas brancas que desejam dar "um passo adiante" na luta racial, podem sair do ciclo que até então vêm se mantendo, de denunciar o racismo no outro, não se reconhecendo beneficiário do mesmo. Superar a visão limitada que confunde racismo com discriminação de raça, com algo pontual, ao invés de enxergá-lo - assim como o capitalismo - como um sistema permanente e em constante atuação, privilegiando uns, ao passo que violenta outros. "Ser racista é um aprendizado que pode ser 'desaprendido' com o reconhecimento dos privilégios de ser branco e com vigilância para evitar legitimação e reprodução do racismo" (SCHUCMAN, 2012, 2015). Nesse sentido, faz-se urgente uma postura orientada para um processo que enseje o grupo racial branco "descolonizarse", ou seja, segundo concepções sartreanas, extirpar "por meio de uma operação sangrenta, o colono que há em cada um".

Se a colonização é um sistema de poder, os brancos que nascem imersos nesse contexto, aprendem, dentre outras coisas, a reproduzi-lo. Damos aquilo que temos. Conforme Memmi (2007) o colonizado deve superar também em si o colonizado, bem como o europeu deve destruir em si o colonizador. É preciso um processo educativo que forneça aos brancos que ainda não tem a consciência crítica sobre o assunto, que ainda não despertaram para confrontar a própria branquitude, referenciais para que os mesmos, através de "uma operação sangrenta", ou seja, radical, descolonizem-se. Um exemplo desse processo de "coragem" e renúncia está bem expressada na composição mais contundente e autocrítica de Preto $\mathrm{Du}$, de sugestivo título "Branquitude"16.

Toda contribuição minha ainda é pouca Trago no sangue os genes de quem rouba Rouba sonhos, rouba o conforto do lar Rouba tudo, e não aceita se você roubar Sou o ladrão da história, e adivinha o que eu roubei?

Roubei sua voz e me reinventei

\footnotetext{
${ }^{16}$ Uma das suas várias obras incompletas e ainda não lançadas.
}

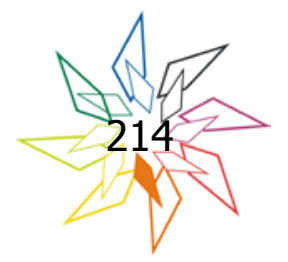


Roubei a sua versão dos fatos e me editei

E vendi a mentira que eu mesmo comprei

Me viciei e hoje roubo por compulsão

Cleptomaníaco, maníaco por alienação

Porque eu sou branco, e minha família deve

Estou devendo até as calças, e o suor da minha pele

Porque eu sou branco e minha família deve

Perdeu seu iphone? Bota na conta da branca de neve

Branquinho se borra todo, "olha o bicho papão"

Quando fala de cotas e indenização

Olhe no currículo, em negrito minha especialização

Perito em manipulação

Desde o fio do cabelo até a minha oração

Mas você não percebe, está de cara pro paredão

O tempo passa e nem reparamos

Que a maioria não tem sucesso em seus Ramos

É que quando chegamos, sujamos

E não reparamos os danos

Na obra, o artista se comporta como uma espécie de Robin Hood "denegrido", que "rouba a voz" da classe dominante branca, seus discursos de mérito e igualdade com base no mito da democracia racial. Através desses, ele se reelabora e alimenta novos argumentos, com a intenção de ferir a quem sempre feriu e não admite ser ferido. A quem sempre impediu a maioria não-branca, de ter "sucesso em seus Ramos". Como propõe Sartre (idem), o rapper "corta a própria carne", reconhecendo-se herdeiro de privilégios duradouros e consequentemente de uma dívida, sobretudo moral, contraída pelos seus antepassados e mantida, em algum nível, pelos seus pares e família. Ele prossegue:

Preto Du, o funcionário da limpeza

Cuspindo no seu padrão de beleza

Eu prefiro o assassinato à omissão

Então eu vou assassinar essa conspiração

Com o dedo na ferida até ferir o meu dedo

Vou abrir a porta do camarote sem medo

Porque eu devo, devo e não nego

Pago quando puder, e agora eu posso

E pra você que se faz de cego

Piso nos seus destroços e me coço

Porque eu sou branco e me sinto endividado

Tenho privilégios e sei que isso é errado 
Resta saber em que medida o artista de fato "cospe no padrão de beleza" que ele próprio usufrui. Seguindo a análise da letra, para quem "se faz de cego", ele aponta a sua justiça. Sua sentença é dura, lembra a fala de Sartre (ibiden, p.14) diante das atrocidades cometidas historicamente pelos europeus:

Quando os camponeses tocam nos fuzis, os velhos mitos empalidecem, e caem por terra, uma a uma, as interdições. À arma do combatente é a sua humanidade. Porque, no primeiro tempo da revolta, é preciso matar; abater um europeu é matar dois coelhos de uma só cajadada, é suprimir ao mesmo tempo um opressor e um oprimido: restam um homem morto e um homem livre; o sobrevivente, pela primeira vez, sente um solo nacional sob a planta dos pés.

Porém, no contexto atual, Preto Du internaliza a posição do oprimido para também fazer a justiça "com suas próprias mãos", na verdade, com seu próprio verbo e ações que buscam contrariar, incomodar, ferir, "matar" de raiva ou vergonha os que se mantêm acomodados na "omissão", para que só assim, quem sabe, uma mudança verdadeiramente profunda aconteça.

Uma auto-descolonização, faria os brancos assumir e defender uma pauta de luta como a narrada por Ngugi Wa Thiong’o (2015), não buscando o protagonismo que pertence aos grupos subalternizados, mas se sentindo corresponsável por uma sociedade mais justa.

$\mathrm{O}$ ato de descolonizar-se envolve um choque redentor. Requer direcionar uma energia tida como negativa, a exemplo da própria raiva, para um fim positivo, a própria transformação. Semelhante a Paulo Freire quando considera:

A minha raiva, minha justa ira, se funda na minha revolta em face da negação do direito de "ser mais" inscrito na natureza dos seres humanos. Não posso, por isso, cruzar os braços fatalistamente diante da miséria, esvaziando, desta maneira, minha responsabilidade no discurso cínico e "morno", que fala da impossibilidade de mudar porque a realidade é mesmo assim. O discurso da acomodação ou de sua defesa, o discurso da exaltação do silêncio imposto de que resulta a imobilidade dos silenciados, o discurso do elogio da adaptação tomada como fado ou sina é um discurso negador da humanização de cuja responsabilidade não podemos nos eximir. (FREIRE, 2000, p.36).

Uma vez que os privilégios exercem um fascínio sedutor e hipnotizante, a autodescolonização é um exercício de desprendimento que só terá eficácia enquanto radical e inegociável, com os próprios privilégios e do grupo racial branco. E por isso precisa ser, em alguma medida, público (CARDOSO, 2008), testemunhado e permanentemente vigiado. "A descolonização jamais passa despercebida porque atinge o ser, modifica fundamentalmente o ser", introduzindo no mesmo "um ritmo próprio, transmitido por homens novos, uma nova linguagem, uma nova humanidade. A descolonização é, em verdade, criação de homens novos." (FANON, 1968, p.26).

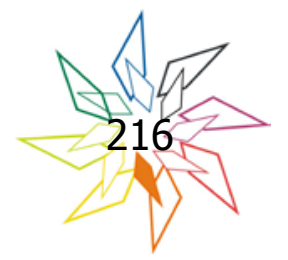




\section{REFERÊNCIAS}

BARBOSA, Lícia Maria de Lima. "Eu me alimento, eu me alimento, força e fé das iabás buscando empoderamento!" : expressões de mulheres negras jovens no Hip-hop baiano. Tese (doutorado) - Universidade Federal da Bahia, Faculdade de Filosofia e Ciências Humanas, Programa Multidisciplinar de Pós-Graduação em Estudos Étnicos e Africanos, 2013.

BHABHA, Homi (2005). O Local da Cultura, Belo Horizonte, Editora UFMG

CARDOSO, Lourenço. O branco "invisível": um estudo sobre a emergência da branquitude nas pesquisas sobre as relações raciais no Brasil (Período: 1957-2007). Dissertação. Faculdade de Economia e Centro de Estudos Sociais da Universidade de Coimbra, Coimbra. 2008.

O branco ante a rebeldia do desejo: um estudo sobre a branquitude no Brasil. Tese (doutorado) - Universidade Estadual Paulista Júlio de Mesquita Filho, Faculdade de Ciências e Letras (Campus de Araraquara). 2014.

CÉSAIRE, Aimé. Discurso sobre o Colonialismo. Lisboa, Sá da Costa, 1978

FANON, Frantz. Pele negra, máscaras brancas. Tradução de Renato da Silveira. Salvador: EDUFBA, 2008.

Os condenados da Terra. Rio de Janeiro, RJ: Civilização Brasileira, 1968.

FREIRE, Paulo. Pedagogia do Oprimido. Rio de Janeiro: Paz e Terra, 1987.

Educação e mudança. $6^{\mathrm{a}}$ ed, Rio de Janeiro, Paz e Terra, 1983

1996.

Pedagogia da autonomia: saberes necessários à prática educativa. São Paulo: Paz e Terra, . Pedagogia da Indignação: cartas pedagógicas e outros escritos. São Paulo: UNESP, 2000.

FREUD, Sigmund. O Mal-Estar na Civilização. Rio de Janeiro: Editora Imago, 1997.

HALL, Stuart. A identidade cultural na pós-modernidade. Tradução: tomaz Tadeu da Silva e Guacira Lopes Louro. Rio de Janeiro, 11 ${ }^{\mathrm{a}}$ edição em 2006.

HELLER, A. O homem do Renascimento. Lisboa: Presença, 1982. 
JESUS, Rodrigo Marcos de. O Humanismo Social de Paulo Freire. 2010. Disponível em: http://www.tjmg. jus.br/data/files/5B/61/F4/1C/469D8310DACF8D83180808FF/pal032010.pdf. Acesso em: maio/2015

NOGUEIRA, Simone Gibran. Psicologia crítica africana e descolonização da vida na prática da capoeira Angola. Tese. PUC - SP. São Paulo. 2013

MEMMI, Albert Retrato do Colonizado Precedido de Retrato do Colonizador. Rio de Janeiro, Civilização Brasileira, 2007.

MIRANDA, Jorge Hilton de Assis. Perspectivas de rappers brancos/as brasileiros/as sobre as relações raciais: um olhar sobre a branquitude. Salvador, 2015. Dissertação (Mestrado). Programa de Pós-Graduação em Educação e Contemporaneidade. Universidade Estadual da Bahia - UNEB.

PIZA, Edith. 2003. Porta de Vidro: Entrada para a Branquitude. In: Iray CARONE \& Maria Aparecida BENTO. Orgs. Psicologia Social do Racismo: estudos sobre branquitude e branqueamento no Brasil. Petrópolis: Editora Vozes, 2003.

SCHWARCS, Lilia Moritz. O espetáculo das raças: cientistas, instituições e questão racial no Brasil -1870-1930. São Paulo: Companhia das Letras, 1993.

SCHUCMAN, Lia Vainer. Entre o "encardido", o "branco" e o "branquíssimo": Raça, hierarquia e poder na construção da branquitude paulistana. Tese. Doutorado. USP. São Paulo, 2012.

Branquitude e poder: revisitando o "medo branco" no século XXI. Revista da ABPN, América do Norte, 6, jun. 2014.

SKIDMORE, Thomas E. Preto no branco: raça e nacionalidade no pensamento brasileiro. Rio de Janeiro: Paz e Terra, 1976.

SOVIK, Liv. Aqui ninguém é branco. Rio de Janeiro: Aeroplano, 2009.

Por que tenho razão: branquitude, Estudos Culturais e a vontade de verdade acadêmica. Contemporânea - Revista de Comunicação e Cultura, v. 3, n. 2, 2005.

THIONG’O, Ngugi Wa. Descolonizar la mente, La política lingüística de la literatura africana. Debolsillo, 2015. 